\title{
ЗАКОНОМЕРНОСТЕЙ ВОССТАНОВЛЕНИЯ ЖЕЛЕЗОРУДНОГО КОНЦЕНТРАТА МОНГОЛИИ УГЛЕМ
}

\author{
Амдур А.М. ${ }^{1}$, Лхамсурэн Мунхтуул. ${ }^{1,2}$, Благин Д.В. ${ }^{1}$, Разничина А.Л. ${ }^{l}$ \\ ${ }^{\prime}$ Уральский государственный горный университет Россия, г. Екатеринбург \\ ${ }^{2}$ Институт химии и химической технологии МАН, Монголия, г. Улан-Батор
}

\section{Введение}

Создание производства чугуна и стали в Монголии - важная государственная задача и научно-техническая проблема. Страна обладает крупными ресурсами железных руд и бурого угля. Исходя из имеющихся ресурсов, необходимо развивать бескоксовую схему производства стали металлизованное сырье - дуговая сталеплавильная печь (ДСП), которая является наиболее высокотехнологичной. Ее главный элемент - металлизация. В качестве восстановителя следует использовать местные угли.

Для разработки научных основ технологии металлизации необходимо выбрать уголь в качестве восстановителя, оптимизировать температуру процесса, время выдержки и содержание восстановителя, а также получить продукт достаточной прочности.

\section{Основные исследования}

Как восстановители исследовали бурые (месторождение Шарынгол) и тощие (месторождение Сайхан-Ово) угли со следующими показателями соответственно,\%: содержание летучих $\mathrm{V}^{\mathrm{daf}}=36,88 ; 8,76$, содержание золы $\mathrm{A}^{\mathrm{d}}=7,67 \% ; 15,78$, содержание серы $\mathrm{S}_{\mathrm{t}}^{\text {daf }}=0.58 ; 0,37 \%$ углерода $\mathrm{C}^{\mathrm{daf}}=77,0 ; 85,0 . \quad$ В качестве объекта исследования был выбран концентрат железных руд, полученный методом мокрой магнитной сепарации, состав которого приведен в табл. 1. Восстановительная способность углей и восстановимость концентратов Монголии слабо изучены. Эти процессы исследовались нами весовым методом.

Таблица 1. Химический состав железорудного концентрата

\begin{tabular}{|c|c|c|c|c|c|c|c|c|c|c|c|}
\hline \multicolumn{10}{|c|}{ Содержание компонентов, \% масс. } \\
\hline $\mathrm{SiO}_{2}$ & $\mathrm{Al}_{2} \mathrm{O}_{3}$ & $\mathrm{TiO}_{2}$ & $\mathrm{Fe}_{2} \mathrm{O}_{3}$ & $\mathrm{FeO}$ & $\mathrm{SO}_{3}$ & $\mathrm{MgO}$ & $\mathrm{CaO}$ & $\mathrm{V}_{2} \mathrm{O}_{5}$ & $\mathrm{NiO}$ & $\mathrm{P}_{2} \mathrm{O}_{5}$ & $\mathrm{Fe}_{\text {обш }}$ \\
\hline 5,97 & 1,58 & 0,15 & 78,51 & 8,94 & 0,014 & 3,99 & 1,3 & 0,090 & 0,020 & 0,21 & 63,45 \\
\hline
\end{tabular}

Экспериментально установлено, что восстановительная способность молодых бурых углей значительно выше, чем тощих каменных, рис. 1.

При восстановлении бурым углем достигается высокая степень металлизации $\varphi_{\mathrm{M}}=\mathrm{Fe}_{\text {мет }} / \mathrm{Fe}_{\text {общ }}$ (до 96-98\%). Содержание $\mathrm{FeO}$ в этом случае изменяется в пределах 1,5 - 
7,2\%, пустой породы 14 - 19\%. Количество пустой породы в полученном металлизованном продукте значительно выше, чем в традиционно используемом в качестве шихты для ДСП. Это связано в первую очередь с низким $\mathrm{Fe}_{\text {общ }}$ в исходном концентрате. Поэтому нами предложена схема обогащения, дающая возможность существенно повысить содержание железа. Определены основные технологические параметры процесса металлизации, позволяющие получать продукты необходимого качества.

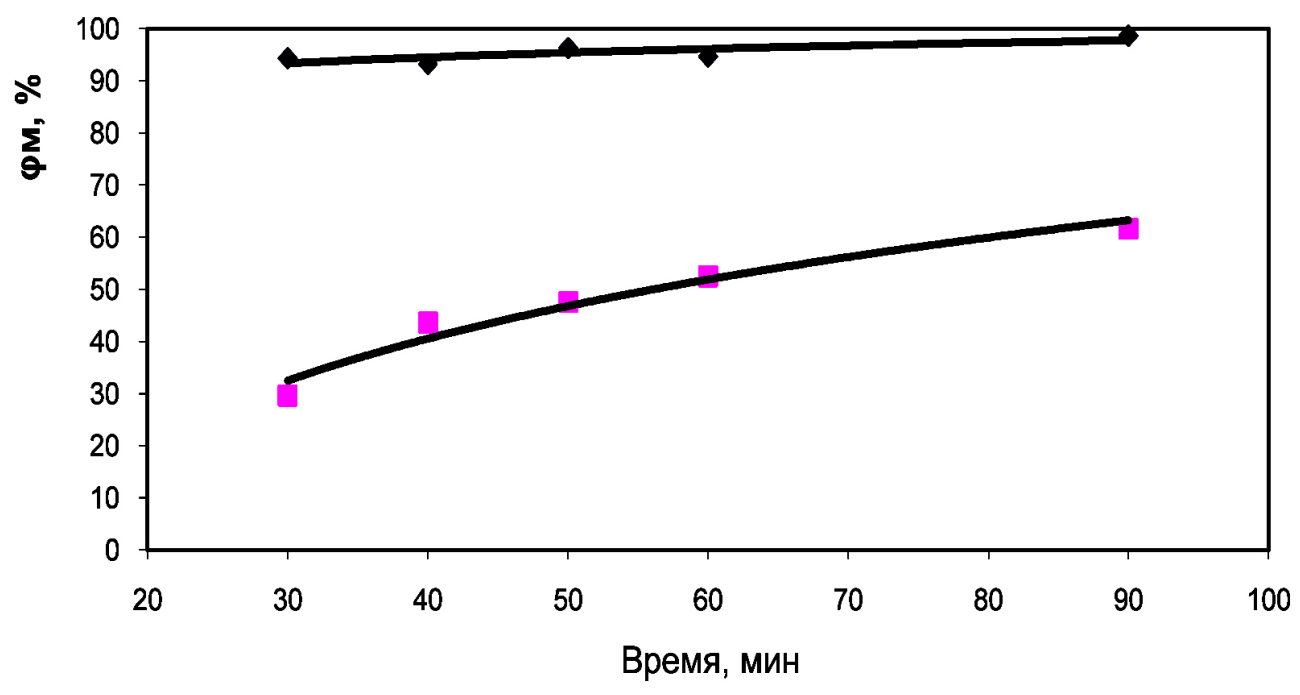

- бурый уголь, - - тощий уголь. Т=1000 ㄷ; С/Cст=100\%.

Рисунок 1. Зависимость степени металлизации от времени выдержки

Уголь содержит значительное количество летучих компонентов- низкомолекулярных продуктов его термической деструкции: от 4-6\% в антрацитах, 14-16\% в тощих углях и до $35-40 \%$ в бурых. Термическая деструкция каменного угля является сложным процессом, который состоит из следующих стадий. 1. Испарение и сублимация низкомолекулярных веществ, кипящих при невысоких температурах. 2. Механическая возгонка (пульверизация газом) жидких составных частей топлива. 3. Крекинг, то есть разрыв цепей органических соединений по линии связи - C - C -. 4. Деполимеризация органических соединений, протекающая при температуре выше $300{ }^{\circ} \mathrm{C}$. 5. Диссоциация термически нестойких комплексов кислот и оснований.

Между тем, экспериментальные данные о составе первичных газообразных продуктов термической деструкции каменного угля крайне ограничены, а их роль в процессе металлизации железорудных концентратов не изучена.

Термическую деструкцию каменного угля изучали с помощью термоанализатора STA 449C Jupiter, оборудованного масс-спектрометром QMC 230. Следует отметить, что термоанализатор, позволяет определять небольшие изменения массы и тепловые эффекты с высокой точностью: точность взвешивания - $10^{-8}$ г, погрешность измерения тепловых эффектов - 1 мВ. Это дает возможность проводить опыты с монослоями частиц угля, что исключает вторичное взаимодействие продуктов его термической деструкции. Приборы такого уровня ранее не использовались для изучения каменных углей.

Исследуемые образцы готовили из природного каменного угля, содержащего около 4\% 
(мас.) летучих, в виде порошков крупностью - 0,5 мм или 0,5-2 мм. Частицы крупностью 0,5-2 мм (первая серия опытов) или -0,5 мм (вторая серия) укладывали в виде монослоя, в третьей серии опытов частицы крупностью 0,5-2 мм укладывали в несколько слоев. Масса навесок составляла 10,31 - 31,18 мг. Опыты проводили в токе аргона (скорость подачи 30 мл/мин), содержание кислорода в атмосфере печи было ниже чувствительности массспектрометра, скорость нагрева - 10 град/мин. Согласно ГОСТ РФ 1238-02 определение содержания летучих компонентов в каменных углях производится при температуре $800{ }^{\circ} \mathrm{C}$, поэтому нагрев образцов проводили до этой температуры.

Результаты опытов в виде кривых изменения веса, скорости изменения веса, ДСК (дифференциально-сканирующая калориметрия) с эталонным образцом из лейкосапфира и результаты масс-спектрометрического анализа газовой фазы показаны на рис. 2-4.

Из рис. 2 видно, что нагрев угля в инертной атмосфере сопровождается убылью массы образцов и эндотермическими эффектами. Общая убыль массы соответствует суммарному содержанию воды и летучих компонентов, определенных химическим анализом. Согласно данным масс-спектрометрического анализа, рис. 3-4, основными компонентами газовой фазы при термической деструкции угля с высокой степенью метаморфизма являются $\mathrm{CH}_{4}$, $\mathrm{CO}_{2}, \mathrm{H}_{2}$ и $\mathrm{H}_{2} \mathrm{O}$. Содержание $\mathrm{C}_{\mathrm{n}} \mathrm{H}_{\mathrm{m}}$ и $\mathrm{N}_{2}$, вероятно, не превышает $1 \%$ (об.) и поэтому не фиксируется использованным нами масс-спектрометром. Состав газовой фазы значительно меняется в зависимости от температуры. Интенсивное выделение метановых углеводородов относиться к периоду $440-500{ }^{\circ} \mathrm{C}$, а содержание в газе $\mathrm{CO}_{2}$ постепенно снижается. При $580{ }^{\circ} \mathrm{C}$ в составе газа начинает преобладать водород. Выше этой температуры содержание водорода возрастает, а содержание метана сокращается, что связано, видимо, со смещением равновесия реакции $\mathrm{CH}_{4}=\mathrm{C}+\mathrm{H}_{2}$ в сторону ее продуктов.

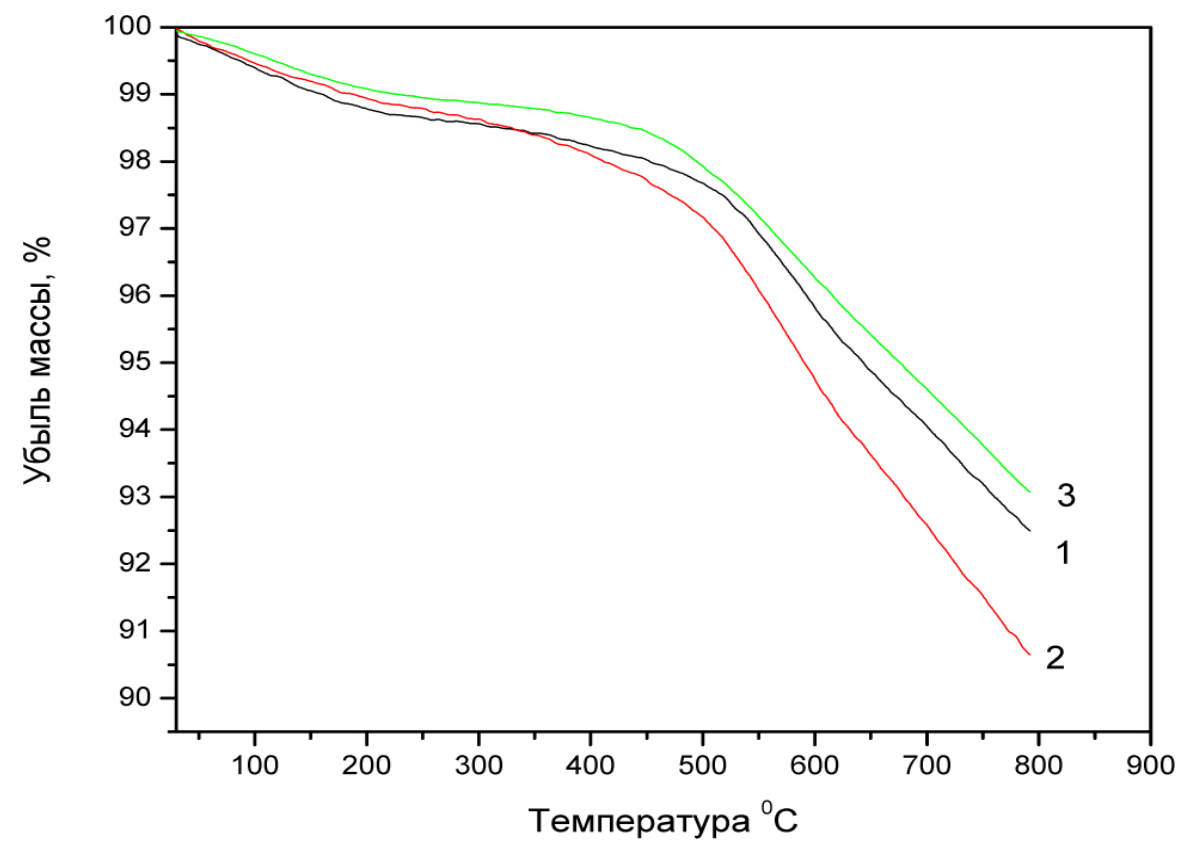



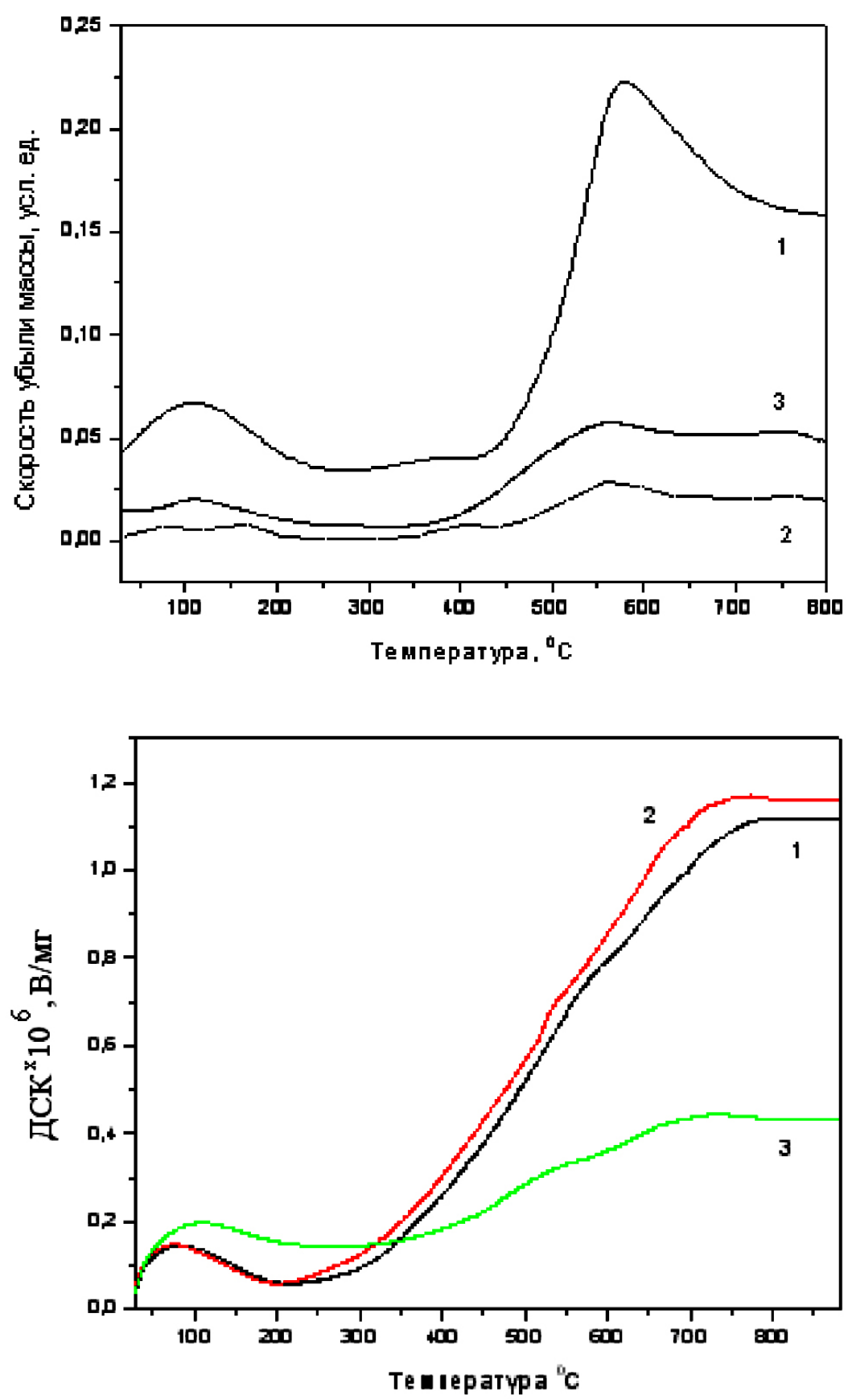

Рисунок 2. Кривые убыли массы ( TG), скорости убыли массы ( DTG ) и ДСК при термической деструкиии каменного угля:

1 - монослой крупностью 2-0,5 мм;

2 -монослой крупностью < 0,5 мм;

3 - несколько слоев крупностью 2-0,5 мм. 


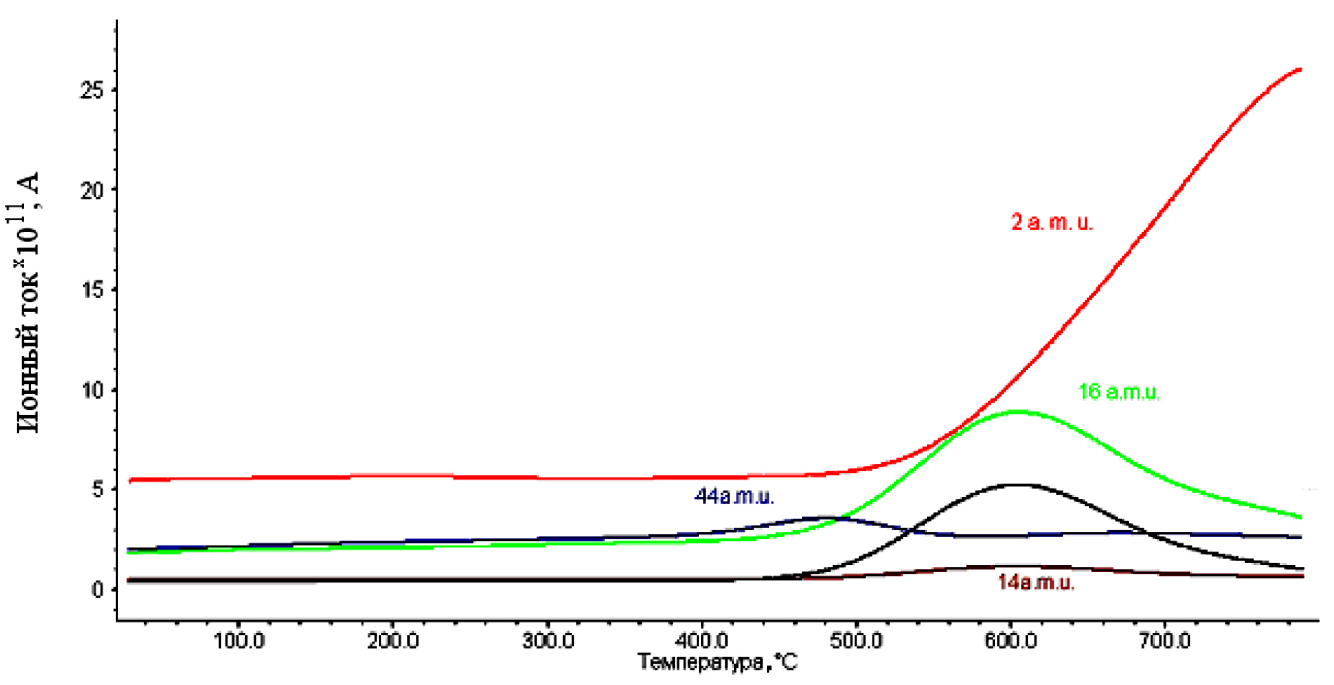

Рисунок 3. Результаты масс-спектрографического анализа газовой фазы при термической деструкиии: иифры у кривых - атомная масса, а.е.м.; 14- $16-\mathrm{CH}_{4} ; 44-\mathrm{CO}_{2} ; 2-\mathrm{H}_{2}$.

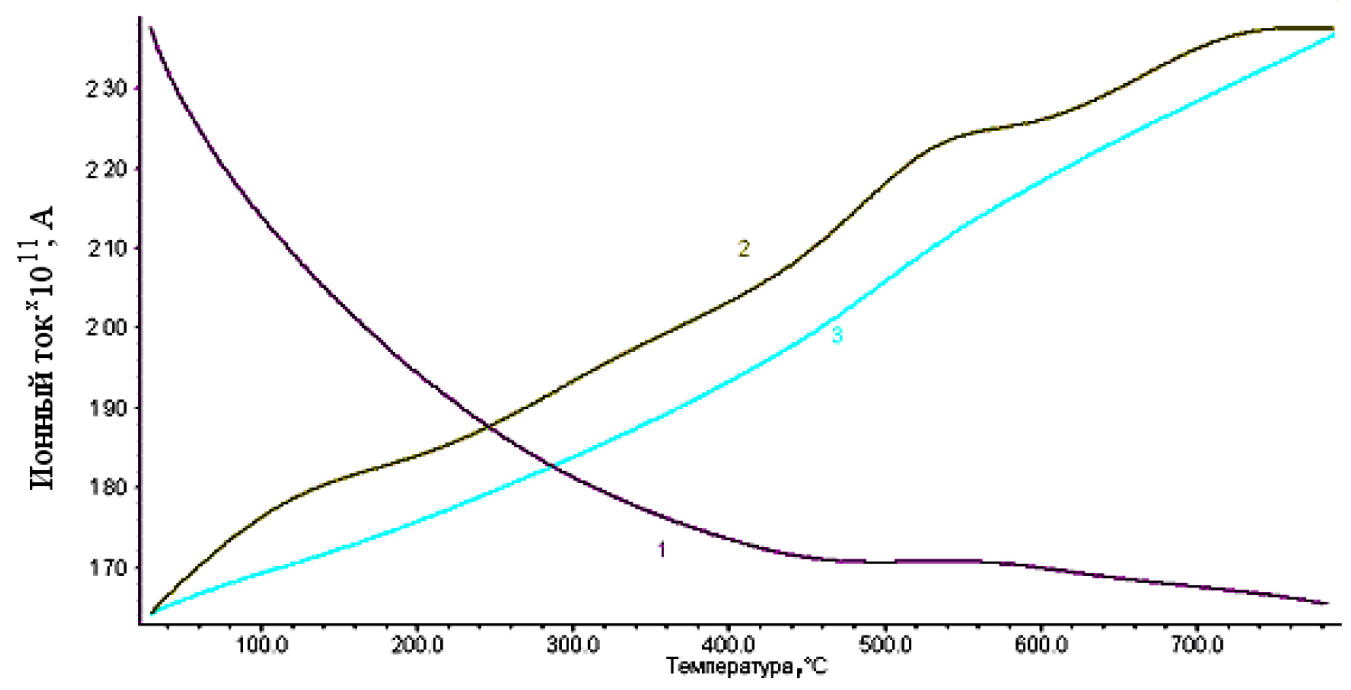

Рисунок 4. Результаты масс-спектрографического анализа воды: иифры у кривых - номер серии опытов.

Первый эндотермический эффект на кривых ДСК, который заканчивается при 200-220 ${ }^{\circ} \mathrm{C}$, связан с испарением свободной воды, так как убыль веса (рис. 2) хорошо согласуется с ее содержанием (1,5\% масс.), определенным химическим анализом. Уголь содержит также около 3,5\% масс. гигроскопической влаги, которая продолжает удаляться при более высоких температурах. Действительно, по данным масс-спектрографического анализа 
вода присутствует в газовой фазе до $700-800{ }^{\circ} \mathrm{C}$. Поэтому тепловой эффект ее испарения при температурах выше 200-220 ${ }^{\circ} \mathrm{C}$ накладывается на эффект, связанный с образованием летучих.

Поведение воды при нагреве образцов разных размеров и объема различно, рис. 4. Вероятно, увеличение количества воды (серии 2-3) с ростом температуры обусловлено образованием пирогенной воды - продукта синтеза водородных радикалов и гидроксогрупп при термическом разложении макромолекул угля в процессе нагрева ([1]). В образцах серии 2 и 3 образование пирогенной воды более вероятно. Действительно, при глубоком измельчении (2-я серия) нарушается структура макромолекул угля ([2]), повышается его реакционная способность, что облегчает синтез пирогенной воды. Если образец состоит из нескольких монослоев, возможно взаимодействие летучих, выделяющихся из нижних слоев частиц угля с другими слоями (3-я серия). Перечисленные эффекты маловероятны в образцах, состоящих из монослоя крупных частиц угля (1-я серия), поэтому синтез воды затруднен, и ее общее содержание при нагреве падает.

Второй эндотермический эффект начинается при температуре $250{ }^{\circ} \mathrm{C}$ и связан, как уже отмечено, с образованием низкомолекулярных продуктов термической деструкции. На кривых ДСК во всех сериях опытов наблюдаются изгибы, рис. 2, что свидетельствует о многостадийном характере этого процесса.

Кривые скорости убыли веса (DTG) для изученных образцов имеют схожий характер, рис. 2. Как и кривые ДСК, они имеют два эффекта, первый из которых относится к испарению воды, второй - к образованию летучих. Однако, скорость выделения летучих компонентов из монослоя частиц крупностью 0,5-2 мм, как и скорость испарения воды, значительно выше, чем для других серий опытов. Аналогичная зависимость была выявлена для коксующихся и жирных углей ([3]). Вероятно, это связано с тем, что, как при глубоком измельчении (фракция -0,5 мм), так и слое частиц создаются условия, тормозящие термическую деструкцию угля.

Весовым методом исследовано влияние летучих компонентов угля на процесс металлизации железорудного концентрата.

Образцы для опытов готовили в виде цилиндров размером 21 х 6 мм путем прессования смеси концентрата крупностью менее 0,01 мм, бурого угля крупностью менее 0,02 мм и бентонита в качестве связующего крупностью менее 0,02 мм. 


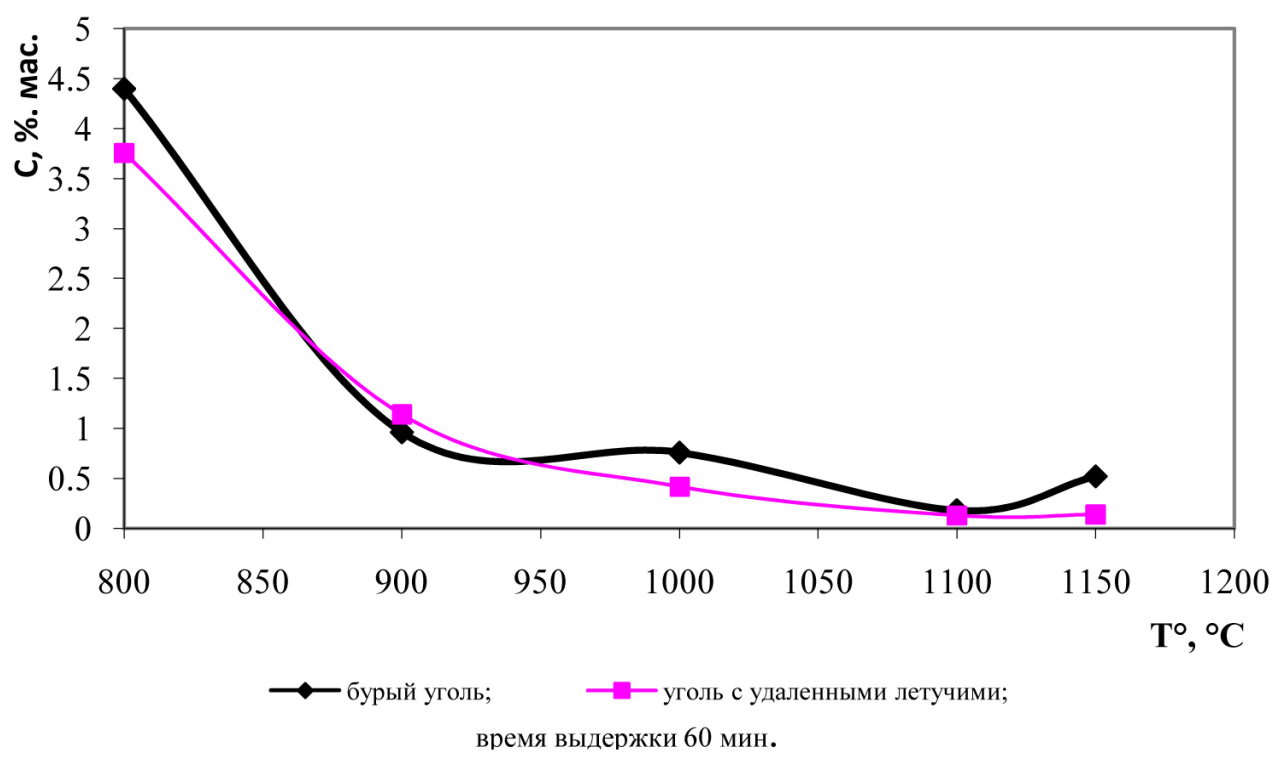

Рисунок 5. Содержание углерода в брикетах после металлизации углем с летучими компонентами и без них при $\mathrm{C} / \mathrm{C}_{c m}=1$

Для предварительного удаления летучих компонентов и влаги измельченный уголь подвергали термической обработке в токе $\mathrm{CO}_{2}$ при температуре $650{ }^{\circ} \mathrm{C}$ в течение часа. Зафиксированное уменьшение массы согласуется с данными технического анализа по содержанию влаги и летучих в угле.

Результаты по содержанию углерода в конечном продукте (степень металлизации изменялась от $44,3 \%$ при $800{ }^{\circ} \mathrm{C}$ до $92,7 \%$ при $1150{ }^{\circ} \mathrm{C}$ ) показаны на рис. 5 . Как следует из рисунка, оно не зависит от того, есть ли в угле летучие компоненты или нет. Следовательно, продукты термической деструкции угля практически не участвуют в науглероживании восстановленных железорудных материалов

Исследование роли летучих компонентов угля на степень металлизации железорудного концентрата показало, что они повышают ее при прочих равных условиях, однако повышение незначительно.

Таким образом, установлена возможность получения металлизованного продукта как шихты для выплавки стали из железорудных концентратов Монголии и вскрыты основные закономерности протекающих при восстановлении углем процессов. 


\section{Заключение}

1. Как восстановители исследовали бурые (месторождение Шарынгол) и тощие месторождение Сайхан-Ово) угли со следующими показателями соответственно, \%: содержание летучих $V^{\mathrm{daf}}=36,88 ; 8,76$, содержание золы $\mathrm{A}^{\mathrm{d}}=7,67 \% ; 15,78$, содержание серы $\mathrm{S}_{\mathrm{t}}^{\mathrm{daf}}=0.58 ; 0,37 \%$ углерода $\mathrm{C}^{\mathrm{daf}}=77,0 ; 85,0$.

2. В качестве объекта исследования был выбран концентрат железных руд, полученный методом мокрой магнитной сепарации, состав которого приведен в табл. 1.

3. При восстановлении бурым углем достигается высокая степень металлизации $\varphi_{\mathrm{m}}=\mathrm{Fe}_{\text {мег }}$ ' $\mathrm{Fe}_{\text {обш }}$ (до 96-98\%). Содержание $\mathrm{FeO}$ в этом случае изменяется в пределах 1,5-7,2\%, пустой породы $14-19 \%$. Количество пустой породы в полученном металлизованном продукте значительно выше, чем в традиционно используемом в качестве шихты для ДСП. Это связано в первую очередь с низким $\mathrm{Fe}_{\text {обш }}$ в исходном концентрате.

4. Для предварительного удаления летучих компонентов и влаги измельченный уголь подвергали термической обработке в токе $\mathrm{CO}_{2}$ при температуре $650{ }^{\circ} \mathrm{C}$ в течение часа. Зафиксированное уменьшение массы согласуется с данными технического анализа по содержанию влаги и летучих в угле. Результаты по содержанию углерода в конечном продукте (степень металлизации изменялась от $44,3 \%$ при $800{ }^{\circ} \mathrm{C}$ до $92,7 \%$ при 1150 $\left.{ }^{\circ} \mathrm{C}\right)$ показаны на рис. 5 . Как следует из рисунка, оно не зависит от того, есть ли в угле летучие компоненты или нет. Следовательно, продукты термической деструкции угля практически не участвуют в науглероживании восстановленных железорудных материалов.

\section{Список литературы}

1. Кинетические исследования процесса скоростного пиролиза углей. Волынкина Е.П., Школлер М.В., Белихмаер Я.А. «Кокс и химия», 1997, № 8 с.5-9.

2. Наука об угле. Ван-Кревлен Д.В., Ж. Шуер., 1985.

3. Оценка эффекта взаимодействия продуктов термической деструкции углей по данным дериватографических исследований. Скляр М.Г. Солдатенко Е.М., Данг В.Х., Каширская Л.П., Воеводина М.В. «Кокс и химия», 1990, № 3, с. 2-4.

Работа выполнена при финансовой поддержке Фонда содействия развитию малых форм предприятий в научно-технической сфере Российской Федерации. 